\title{
Analysis on VAMAS Low Cycle Fatigue Round Robin Test in Japan
}

\author{
Masaki KITAGAWA, Koji YAMAGUCHI, ${ }^{1)}$ Yoshio FUKUDA, ${ }^{2)}$ Ryuji KOMINE ${ }^{3)}$ and Hideyuki HIRATA ${ }^{4)}$
}

Research Institute, Ishikawajima-Harima Heavy Industries, Co., Ltd., Toyosu, Koto-ku, Tokyo, 135 Japan.

1) National Research Institute for Metals, Nakameguro, Meguro-ku, Tokyo, 153 Japan. 2) Mechanical Engineering Research Laboratory, Hitachi, Ltd., Saiwai-cho, Hitachi, Ibaraki-ken, 317 Japan. 3 3) Oharai Engineering Center, Power Reactor and Nuclear Fuel Development Corp., Narita-cho, Oharai, Ibaraki-ken, 311-13 Japan. 4) Heavy Apparatus Engineering Laboratory, Toshiba Corporation, Suehiro-cho, Turumi-ku, Yokohama, Kanagawa-ken, 230 Japan.

(Received on March 1. 1993; accepted in final form on May 21, 1993)

This is a report on discussions at VAMAS-LCF Committee of The Iron and Steel Institute of Japan. The aim of VAMAS Low Cycle Fatigue project is to examine the effects of test variables on high temperature fatigue tests. In Japan ten laboratories participated in the round robin tests. Based on the discussion of international and domestic test results at the committee, solutions were sought to certain problems on high. temperature low cycle fatigue testing and recommendations for methods of testing were made. Investigation was made of the following. One is the effects of a spot-welded thermocouple on test results and alternative methods for temperature measurement, and the other is physical meaning of the number of cycles to failure in high temperature low cycle fatigue.

KEY WORDS: low cycle fatigue; standard testing method; temperature measurement; failure criteria.

\section{Introduction}

VAMAS Low Cycle Fatigue project ${ }^{1)}$ was started in 1987 to examine the effects of test variables on test results as a basis for establishing standard test procedures. Seventeen European and ten Japanese laboratories participated in the round robin tests. The final report ${ }^{2)}$ of testing results was published in the end of 1990 by $\mathrm{G}$. B. Thomas and R. K. Varma of NPL, England.

In Japan, VAMAS-LCF Committee of the Iron and Steel Institute of Japan analyzed the testing results. This report presents the results of investigation on effects of a spot-welded thermocouple, alternative methods for temperature measurement, and physical meaning of fatigue failure criteria.

\section{Materials and Test Procedures}

The materials for testing were AISI $316 \mathrm{~L}$, Modified
9Cr-1Mo, Inconel 718 and Nimonic 101, selected based on cyclic strain characteristics. ${ }^{2)}$ Their chemical compositions and heat treatments are indicated in Table 1. ${ }^{2}$ )

Test conditions are shown in Table 2. ${ }^{2)}$ Each laboratory conducted tests on nine specimens, three for each condition. Strain wave shape was triangular and strain rate $10^{-3} / \mathrm{s}$. Specimen surface finish was below $0.4 \mu \mathrm{m}$ as average surface roughness, according to guideline. ${ }^{3)}$ Other test conditions such as testpiece shape, extensometer type, testmachine type, heating method, temperature measurement technique, alignment procedure for the loading axis and failure criteria are not specified. Each laboratory followed its own procedure for testing, and the details were indicated in the final report. $^{2)}$

\section{Comparison of Test Procedures}

Procedures recommended for low cycle fatigue test

Table 1. Chemical composition and heat treatment of the materials.

\begin{tabular}{|c|c|c|c|c|c|c|c|c|c|c|c|c|c|c|c|c|}
\hline \multirow{2}{*}{ Material } & \multirow{2}{*}{$\begin{array}{c}\text { Heat } \\
\text { treatment }\end{array}$} & \multicolumn{15}{|c|}{ Composition (wt \%) } \\
\hline & & $\mathrm{C}$ & $\mathrm{Si}$ & $\mathrm{S}$ & $\mathbf{P}$ & $\mathrm{Mn}$ & $\mathrm{Ni}$ & $\mathrm{Cr}$ & Mo & $\mathrm{Fe}$ & $\mathbf{N}$ & $\mathrm{Cu}$ & Co & $\mathrm{Ti}$ & $\mathrm{Nb}$ & $\mathrm{Al}$ \\
\hline AISI $316 \mathrm{~L}$ & $1140^{\circ} \mathrm{C} / 40 \mathrm{~min} W Q$ & 0.019 & 0.45 & 0.001 & 0.029 & 1.69 & 12.1 & 17.3 & 2.35 & BAL & 0.069 & 0.295 & 0.13 & 0.005 & 0.005 & 0.032 \\
\hline $9 \mathrm{Cr}-1 \mathrm{Mo}$ & $\begin{array}{l}950^{\circ} \mathrm{C} / 30 \mathrm{~min} \mathrm{AC} \\
760^{\circ} \mathrm{C} / 1 \mathrm{~h} \mathrm{AC}\end{array}$ & 0.08 & 0.254 & 0.0015 & 0.022 & 0.366 & 0.15 & 8.26 & 0.99 & BAL & - & 0.11 & - & - & - & 0.019 \\
\hline IN 718 & $\begin{array}{l}960^{\circ} \mathrm{C} / 1 \mathrm{~h} \mathrm{AC} \\
720^{\circ} \mathrm{C} / 8 \mathrm{~h} \mathrm{FC} \\
620^{\circ} \mathrm{C} / 8 \mathrm{~h} \mathrm{AC}\end{array}$ & 0.023 & 0.03 & 0.0017 & 0.002 & 0.03 & 52.3 & 18.0 & 3.18 & 19.5 & - & 0.005 & 0.02 & 0.98 & 5.35 & 0.49 \\
\hline Nimonic 101 & $\begin{array}{l}1120^{\circ} \mathrm{C} / 1 \mathrm{~h} \mathrm{AC} \\
850^{\circ} \mathrm{C} / 16 \mathrm{~h} \mathrm{AC}\end{array}$ & 0.053 & 0.08 & 0.002 & - & 0.07 & BAL & 24.2 & 1.45 & 0.18 & - & 0.01 & 19.2 & 3.02 & 0.91 & 1.41 \\
\hline
\end{tabular}


Table 2. Testing conditions of VAMAS round robin tests

\begin{tabular}{lcccc}
\hline Material & $\begin{array}{c}\text { Temperature } \\
\left({ }^{\circ} \mathrm{C}\right)\end{array}$ & \multicolumn{3}{c}{ Total strain range (\%) } \\
\hline $316 \mathrm{~L}$ & 550 & 2.0 & 1.2 & 0.6 \\
$9 \mathrm{Cr}-1 \mathrm{Mo}$ & 550 & 2.0 & 1.2 & 0.6 \\
IN 718 & 550 & 2.0 & 1.2 & 1.0 \\
N 101 & 850 & 1.2 & 0.7 & 0.5 \\
\hline
\end{tabular}

Table 3. Specimen type and heating method used at the laboratories of Europe and Japan.

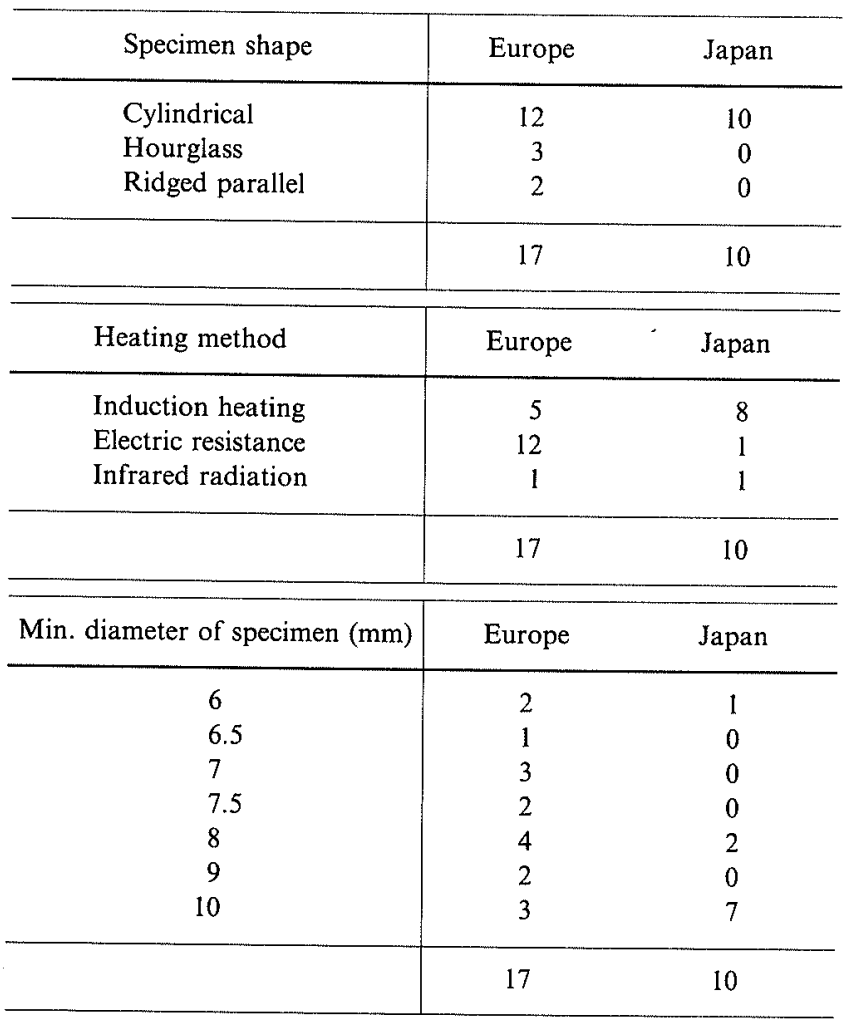

Table 4. Load drop value $(\phi \%)$ for failure criterion.

\begin{tabular}{ccc}
\hline$\%$ & Europe & Japan \\
\hline 1.5 & 1 & 0 \\
5 & 2 & 0 \\
10 & 6 & 0 \\
25 & 9 & 10 \\
50 & 3 & 0 \\
70 & 1 & 0 \\
75 & 1 & 0 \\
90 & 2 & 0 \\
95 & 2 & 0 \\
\hline
\end{tabular}

have been reported ${ }^{4-8)}$ but an international standard has not yet been established.

Table 3 presents the specimen types and heating methods used at the laboratories which participated in this project. $^{2)}$

Low cycle fatigue life at high temperature is the number of cycles to failure $N_{x}$ as well as to complete fracture $N_{f}$. Table 4 shows load drop values used at the laboratories for failure criteria. ${ }^{2}$ European laboratories use various values from 1.5 to $95 \%$, and some use two or three values. In Japan, all laboratories use $25 \%$ after the recommendation of Ref. 5), and its value may be determined based on engineering experience. No definite physical meaning has been specified.

Thomas $^{8)}$ indicates that a thermocouple should be spotwelded on the shoulder for the induction heating. Others recommend spotwelding on the surface of the gage section. ${ }^{5-7)}$ For furnace heating, the thermocouple is usually attached to the gage section by a heat-resistant flexible cord made of glass wool, for instance.

\section{Results of Round Robin Tests}

\subsection{Relationship between Total Strain Range and Number of Cycles to Fracture}

Figure 1 presents Japanese data for four materials to indicate the relationship between total strain $\Delta \varepsilon_{t}$ and number of cycles to fracture $N_{f}$. The broken lines denote $95 \%$ probability of fracture. The data for $316 \mathrm{~L}$ and $9 \mathrm{Cr}-1 \mathrm{Mo}$ steels show merely fair agreement. Inconel 718 shows considerable scatter in low strain range. For Nimonic 101, the tests were conducted at only one laboratory in Japan, and thus the scatter is small.

The final report ${ }^{2)}$ of all the data from Europe and Japan presents the following conclusions.

(1) Within-laboratory variation in $N_{f}$ is significantly less than interlaboratory variation.

(2) Interlaboratory variation is not due to any single major testing variable. The spread of results should be considered to be caused by the use of various current testing procedures.

(3) The spread of $N_{f}$ for $316 \mathrm{~L}$ and $9 \mathrm{Cr}-1$ Mo steels is smaller than that for Inconel 718 and Nimonic 101 alloys.

(4) Testing result is not correlated with sampling position of testpiece, types of testing machine, thermocouple or surface finish of the specimen.

(5) Hour-glass profile testpieces, a ridged testpiece and testpiece of shoulder displacement control produce greater scatter of life and stress than a smooth testpiece of axial strain control.

Japanese data in Fig. 1 all satisfy a condition of a smooth testpiece of axial strain control.

\subsection{Influence of the Method for Thermocouple Attach- ment}

Based on observations of the fracture surfaces, fatigue fracture was shown to start at a small depression for all testpieces of Inconel 718 to which the thermocouple was spotwelded on the gage section, as shown in Fig. 2. Surface defect was due to spotwelding of the thermocouple. In the cases of $316 \mathrm{~L}$ and $9 \mathrm{Cr}-1 \mathrm{Mo}$ steels, the site of crack initiation was there for the only part of the spotwelded testpieces.

Figure 3 shows plastic strain range $\Delta \varepsilon_{p}$ and number of cycles to fracture $N_{f}$ as parameter of the method for attaching the thermocouple and heating the specimen. Figure 3 shows data obtained from international round robin tests which satisfied a condition of a smooth testpiece of axial strain control. This condition is named 

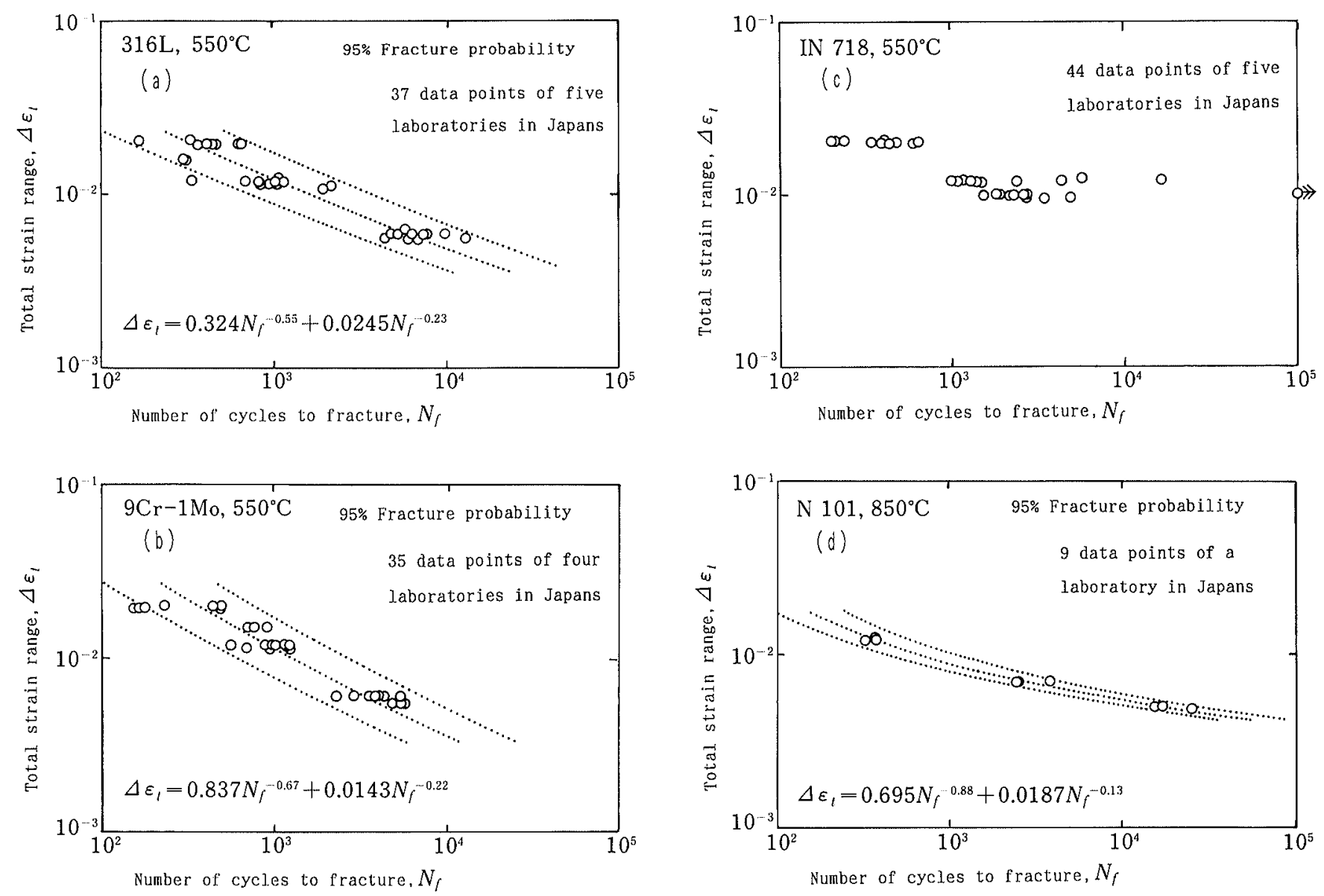

Fig. 1. Relationships between total strain range and number of cycles to fracture for each material.

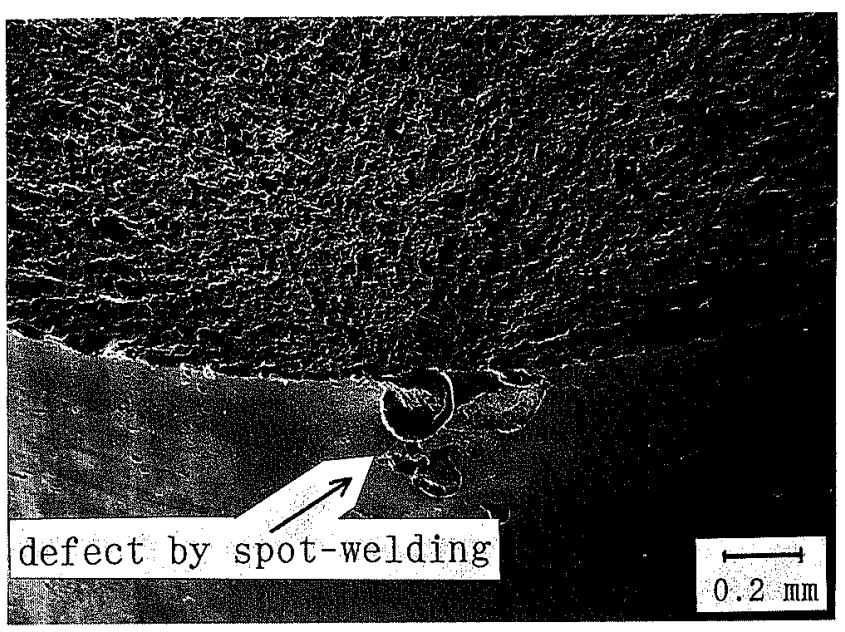

Fig. 2. Fatigue crack initiation site for Inconel 718.

\section{Category $Z$ in the final report. ${ }^{2)}$}

As shown in Fig. 3, the method for thermocouple attachment caused no differences in the data band of $N_{f}$ for $316 \mathrm{~L}$ steel, but some for $9 \mathrm{Cr}-1 \mathrm{Mo}$ steel and considerable differences for Inconel 718. For Nimonic 101, the band of $N_{f}$ was narrow since only one method for attachment was used. However, the data whose attaching method was not reported in the final report ${ }^{2)}$ indicated much shorter fatigue lives. The influence of spotwelding for Nimonic 101, therefore, appears to be large as that for Inconel 718.

\section{Alternative Temperature Measurement Methods and Accuracy}

\subsection{Results of Temperature Measurement}

Induction or infrared heating is often conducted to heat a testpiece in a fatigue test. Temperature is measured and controlled in many cases using a thermocouple spot-welded directly to the gage section of the specimen. These methods are based on the consideration that spotwelding leads to no significantly adverse effect. And this is supported by the past Japanese cooperative studies on ductile materials such as 304 or 316 steels. As shown in Subsec. 4.2, this investigation indicated that spotwelding actually caused such effect for some kinds of steel. Thus, alternative methods for temperature measurement and control have been examined. The results are indicated below.

\section{(1) Radiation Pyrometer}

Table 5 compares values measured by a radiation pyrometer (MINORUTA, IR-308) with those by a spot-welded thermocouple. The specimen was $316 \mathrm{~L}$ steel. The pyrometer showed significant error after $24 \mathrm{hr}$, possibly since oxidation of the specimen surface caused variation in the radiation rate.

\section{(2) Pressure-contact Thermometer}

Table 6 shows values by a pressure-contact thermometer (ANRITU, HL-30). The higher the temperature, the greater is the error, possibly due to thermal dissipation from the contact region. 

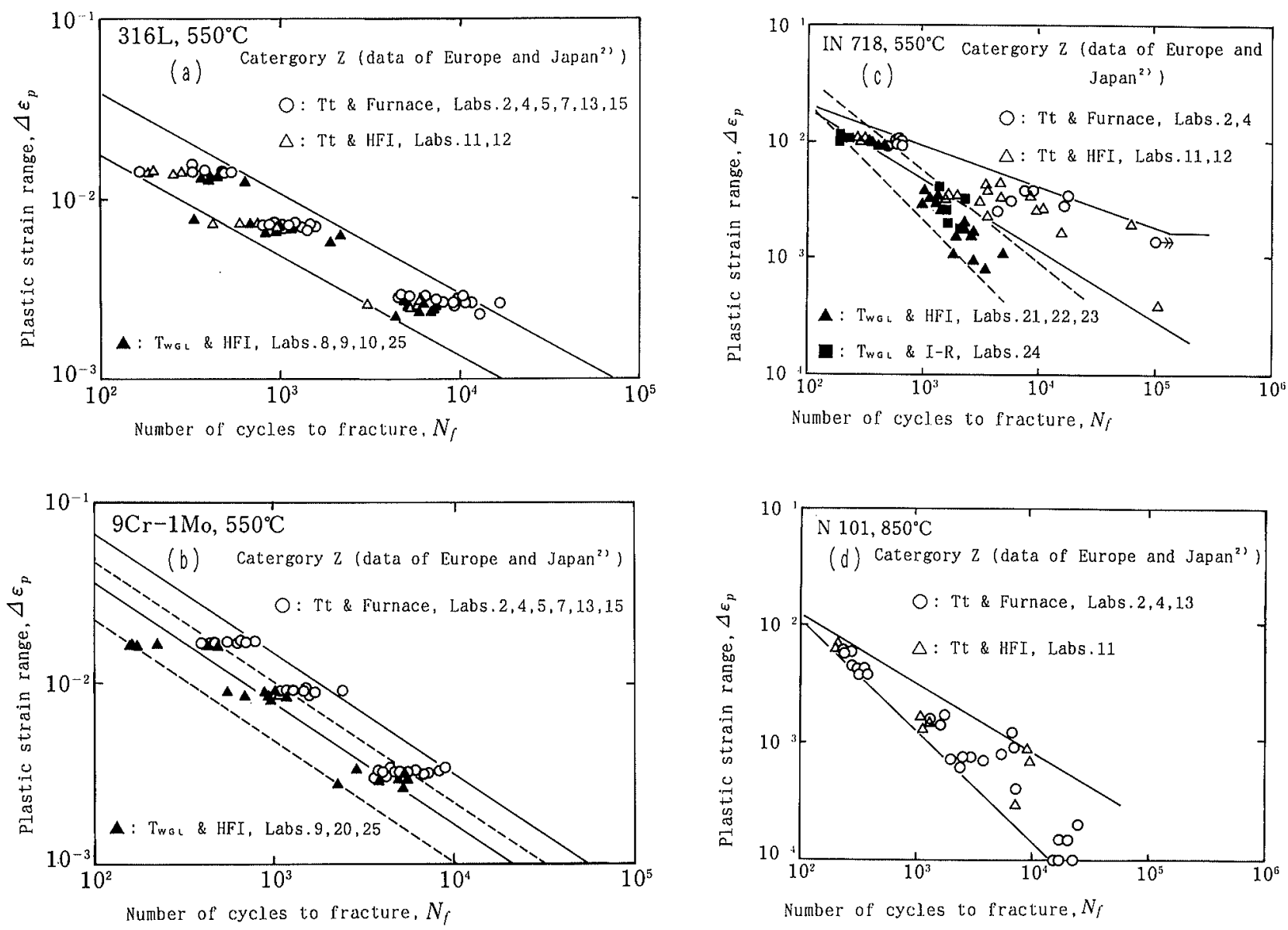

Fig. 3. Relationships between plastic strain range and number of cycles to fracture for each material. Tt: Thermocouple is attached, $T_{w_{G L}}$ : Thermocouple is spot-welded on gage section.

Table 5. Temperature measurement result by pyrometer. $\left({ }^{\circ} \mathrm{C}\right)$

\begin{tabular}{cccccc}
\hline \multirow{2}{*}{$\begin{array}{c}\text { Time } \\
\text { from } \\
\text { heating }\end{array}$} & \multicolumn{2}{c}{ Shoulder } & & \multicolumn{2}{c}{ Gage section } \\
\cline { 5 - 6 } \cline { 5 - 6 } \cline { 5 - 6 } & Thermocouple & Pyrometer & & Thermocouple & Pyrometer \\
\hline $2 \mathrm{hr}$ & 409 & 409 & & $546^{*}$ & $546^{*}$ \\
& 429 & 428 & & 570 & 569 \\
& 458 & 458 & & 611 & 609 \\
$24 \mathrm{hr}$ & 368 & 368 & & 492 & 490 \\
& 413 & 415 & & 550 & 560 \\
\hline
\end{tabular}

* The emissivity is corrected by the data of thermocouple spot-welded to the gage section after $2 \mathrm{hr}$ from heating.

Table 6. Temperature measurement result by pressurecontact thermometer. $\left({ }^{\circ} \mathrm{C}\right)$

$\begin{array}{llllll}\text { Spot-welded thermocouple } & 400 & 450 & 500 & 550 & 600 \\ \text { Pressure-contact thermometer } & 400 & 449 & 498 & 544 & 575\end{array}$

(3) Pressure-contact Thermocouple

In this method, a thermocouple with a welded tip is applied to the specimen surface. Table 7 shows this method produced error by nearly $100^{\circ} \mathrm{C}$. The error depended also on the force of application.

(4) Thermocouple Attached to a Specimen with a Heat-resistant Cord Made of Glasswool

The tip of thermocouple was (a) welded, (b) separated,
Table 7. Temperature measurement result by pressurecontact thermocouple. $\left({ }^{\circ} \mathrm{C}\right)$

\begin{tabular}{lccc}
\hline Spot-welded thermocouple & 500 & 550 & 600 \\
Pressure-contact thermometer & $429-432$ & $463-473$ & $497-510$ \\
\hline
\end{tabular}

Table 8. Temperature measurement result by thermocouple attached to gage section with glasswool cord. $\left({ }^{\circ} \mathrm{C}\right)$

\begin{tabular}{cl|ccc}
\hline Spot-welded thermocouple & 500 & 550 & 600 \\
\hline & (1) welded tip & 469 & 520 & 567 \\
Thermocouple & (2) separated tips & 489 & 541 & 592 \\
tied with & (3) welded and & - & $547-551$ & - \\
glasswool & $\begin{array}{l}\text { hammered tip } \\
\text { (4) separated and } \\
\text { hammered tips }\end{array}$ & 503 & 548 & 601 \\
\hline
\end{tabular}

(c) welded and hammered out flatly and (d) separated and hammered out flatly.

The thermocouple was a R-type of $0.3 \mathrm{~mm}$ in diameter. Table 8 shows that the two methods with flattened tips provide nearly the same accuracy as a spot-welded thermocouple. However, durability (tension) of the cord and oxidation of specimen surface may make it impossible to measure temperature stably over a long period of time. The output was found to change by five to ten degree $\mathrm{C}$ during a fatigue test at $550^{\circ} \mathrm{C}$ over eight hours. ${ }^{9)}$ 


\subsection{Temperature Measurement Methods Suitable for High Temperature Low-cycle Fatigue Tests}

From above investigation, a low-cycle fatigue test would be able to be carried out without spot-welding a thermocouple on the gage section even for induction heating under the following conditions.

(1) Induction heating should be controlled by spotwelded thermocouple on the shoulder of the specimen to obtain a stable feedback signal.
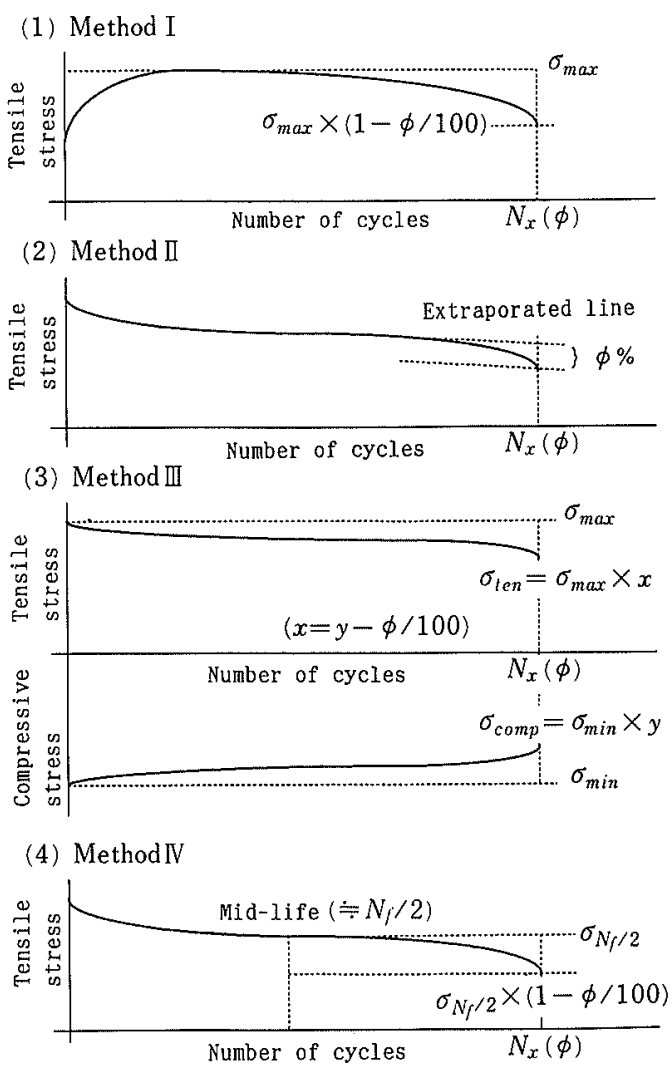

Fig. 4. Four determination methods of number of cycles to failure $N_{x}$
(2) Temperature of the gage section should be measured by a thermocouple with flattened tips attached to the gage section with a heat-resistant cord such as one of glass wool or a radiation pyrometer during the start of the test.

\section{Failure Criterion of Low Cycle Fatigue}

Low cycle fatigue life cannot be defined only by a cycle to complete fracture since the test is not load- but strain-controlled and tensile stress decreases gradually with growth of cracks, especially at high temperatures. There are several methods for defining low cycle fatigue failure. ${ }^{4-8)}$. In this study, comparison was made of the number of cycles to failure $N_{x}$ determined by the following four methods using all the Japanese data.

\subsection{Method of Analysis}

Figure 4 shows schematic diagram of the four methods. $N_{x}$ is defined as the number of cycles under the following conditions.

Method I: tensile stress decreased by $\phi \%$ from the maximum tensile stress

Method II: tensile stress decreased by $\phi \%$ from an extrapolation line of peak tensile stress $v s$. cycle

Method III: decrease in tensile stress from the maximum tensile stress exceeded by $\phi \%$ compared with decrease in compressive stress from maximum compressive stress

Method IV: tensile stress decreased by $\phi \%$ from the tensile stress at mid-life, about $N_{f} / 2$ cycles.

In this analysis, 10,25 and $50 \%$ are typical values of $\phi \%$. The quality of each method is compared by slopes in the logarithmic normal distribution of $N_{x} / N_{f}(\%)$.

\subsection{Results of Analysis}

The results are shown in Fig. 5 for each method. For each material the results are summarized in Table 9.

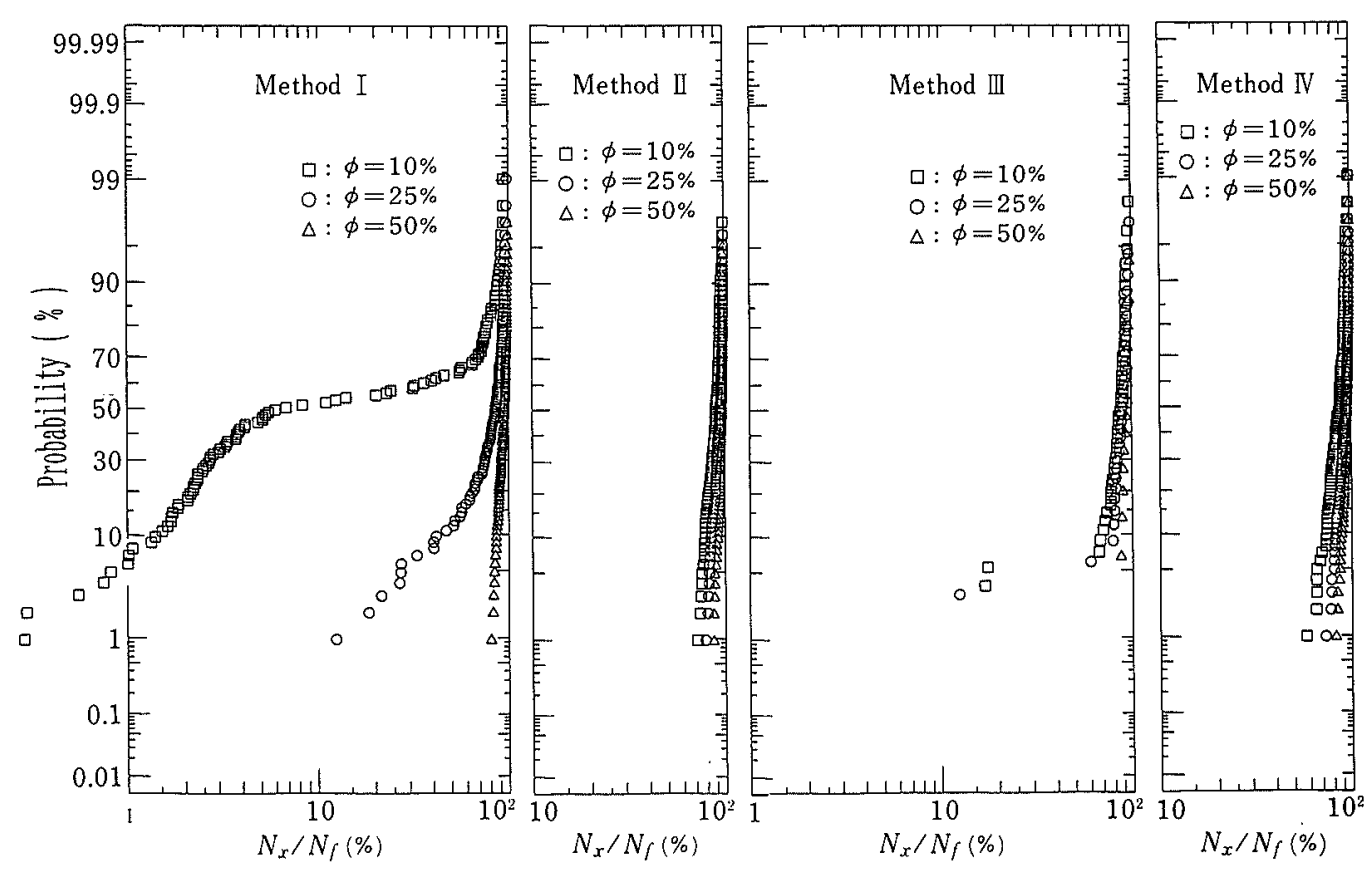

Fig. 5. Logarithmic normal distribution of $N_{x} / N_{f}$ for all the materials. 
Table 9. Summary of logarithmic normal distribution of $N_{x} / N_{f}$ for each material.

\begin{tabular}{|c|c|c|c|c|c|c|c|c|c|c|c|c|}
\hline \multirow{2}{*}{$\begin{array}{c}\text { Material } \\
\qquad \phi \%\end{array}$} & \multicolumn{3}{|c|}{$316 \mathrm{~L}$} & \multicolumn{3}{|c|}{$9 \mathrm{Cr}-\mathrm{IMo}$} & \multicolumn{3}{|c|}{ IN 718} & \multicolumn{3}{|c|}{ N 101} \\
\hline & 10 & 25 & 50 & 10 & 25 & 50 & 10 & 25 & 50 & 10 & 25 & 50 \\
\hline Method I & (ㅇ) & () & (อ) & $x$ & $x$ & (ㅇ) & $x$ & $x$ & (อ) & $x$ & (ค) & () \\
\hline Method II & ( & (อ) & () & (2) & () & ○ & (อ) & (อ) & (ㅇ) & (2) & () & ○ \\
\hline Method III & () & () & () & (2) & ○ & $x$ & $x$ & $x$ & () & $x$ & 0 & $\mathrm{O}$ \\
\hline Method IV & (ㅇ) & ○) & (?) & () & () & () & () & () & () & () & (ㅇ) & () \\
\hline
\end{tabular}

○: small scatter, $\bigcirc$ : medium scatter, $x$ : large scatter.

The characteristics of each method are summarized as follows:

Method I: Though possibly suitable for cyclic hardening material such as $316 \mathrm{~L}$ steel, a large $\phi$ value for cyclic softening material such as $9 \mathrm{Cr}-1 \mathrm{Mo}$ steel is required. There may be a limit for actual $\phi$. This will be discussed in the next chapter.

Method II: This method provides reliable results for every $\phi$ value for each material. It is particularly suitable for softening materials. Analytical trend curve is required for tensile stress $v s$. cycle.

Method III: This method shows much scattering for Inconel 718. Curves of tensile and compressive stresses $v s$. cycles are required to determine the failure point.

Method IV: This method provides reliable results at every $\phi$ value for each material.

Figure 5 indicates that the results by Method II show the least scattering and Method IV gives almost the same result.

The selection of suitable $\phi$ is discussed in the next chapter.

\section{Suitable $\phi$ and Crack Length for Failure Criterion}

\subsection{Relationship between Crack Length and Stress Reduction Ratio}

Figure 6 shows the relationship between cycles ratio $N / N_{f}$ and surface crack length $2 c$, initiated in strain-controlled fatigue tests using a $10 \mathrm{~mm}$ diameter solid cylindrical specimen. Reference data for 304 steel $^{10,11)}$ are also shown. From the figure, fatigue cracking can be seen to be initiated at a cycle ratio between 0.1 and 0.2 , and cracks to propagate rapidly at a cycle ratio over 0.8 .

Although it is appropriate that the number of cycles to failure $N_{x}$ is determined from crack length, it is difficult to measure continuously crack length during a test. Failure criterion has usually been expressed from change in tensile stress.

Figure 7 shows the relationship between crack length and the tensile stress ratio $\sigma / \sigma_{N f / 2}$. Crack length was normalized to $2 c / D$, where $D$ is the specimen diameter. Although the stress ratio decreased generally with increase in crack length, the data band was not very narrow. The cause of scattering is discussed in the following.

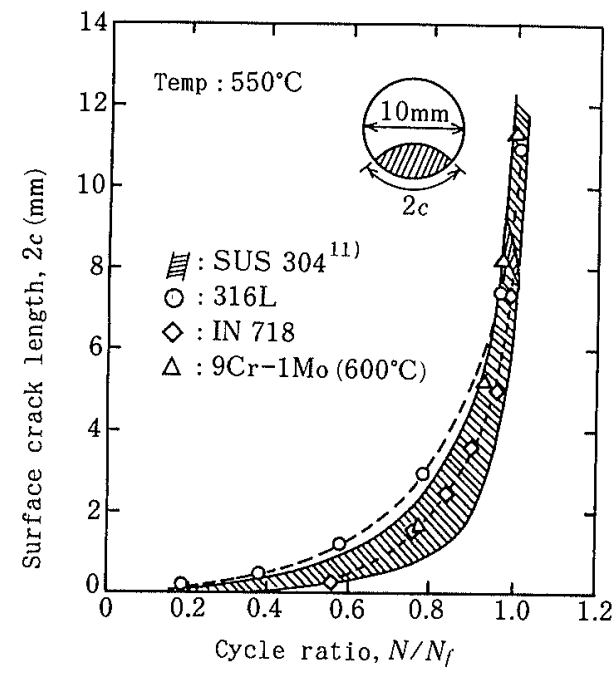

Fig. 6. Relationship between cycles ratio $N / N_{f}$ and surface crack length.

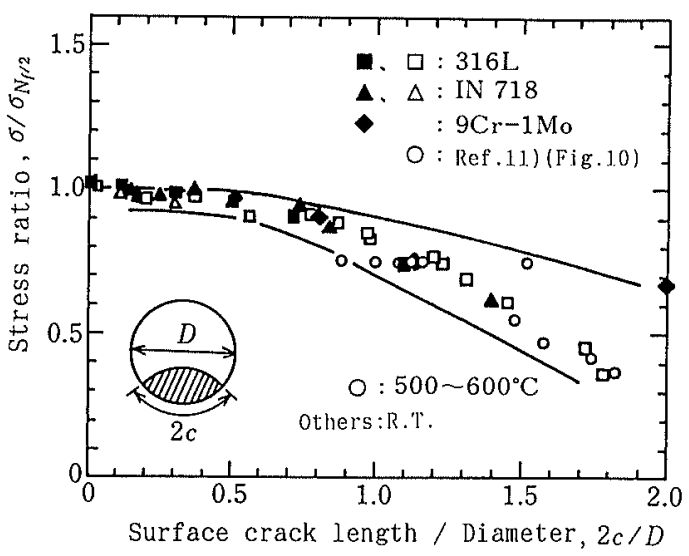

Fig. 7. Relationship between crack length and tensile stress ratio.

\subsection{Locations of Crack and Extensometer}

The influence of extensometer location on change in stress and strain arising from the growth of cracks was examined. Figure 8 shows differences in strain range at the crack side and back side. The boundary conditions of analysis are shown in the top left of the figure. Crack was assumed to be semicircular with a depth of $a$ on the surface of a round bar. $\Delta L / L$, obtained by dividing the cyclical overall displacement of $\Delta L$ by overall length $L$, was the nominal strain range $\Delta \varepsilon_{n} . \Delta \varepsilon_{2} / \Delta \varepsilon_{n}$ and $\Delta \varepsilon_{1} / \Delta \varepsilon_{n}$ varied with crack length owing to bending of the bar, where $\Delta \varepsilon_{2}$ is strain range on the crack side and $\Delta \varepsilon_{1}$ is strain range of the back side. 
In contrast to Fig. 8, Fig. 9 shows cyclic stress range to depend on the location of the extensometer which keeps strain range constant.

The factors shown in Figs. 8 and 9 are thought to be major causes of the scattering in Fig. 7. The relationships shown in Fig. 8 were confirmed by experiment, ${ }^{9)}$ too.

\subsection{Physical Meaning of $N_{x}$}

From Fig. 8, the number of cycles to failure $N_{x}$ should be determined prior to the growth of crack leads to considerable differences in strain ranges on the crack side and the back side.

$N_{x}$ can be determined for the first time when the tensile stress clearly begins to decline. From Fig. 9, when the extensometer is located on the back side of crack, decline begins first when crack depth $a / D$ exceeds 0.4 .

To satisfy the above two conditions, $N_{x}$ should be determined when $a / D$ reaches 0.4 . When $a / D$ is 0.4 , ratio of cracked area to whole cross section of round bar specimen is approximately $25 \%$, geometrically. This is a physical meaning of the conventional definition, ${ }^{5}$ that $N_{x}$ is the number of cycles when tensile stress is reduced

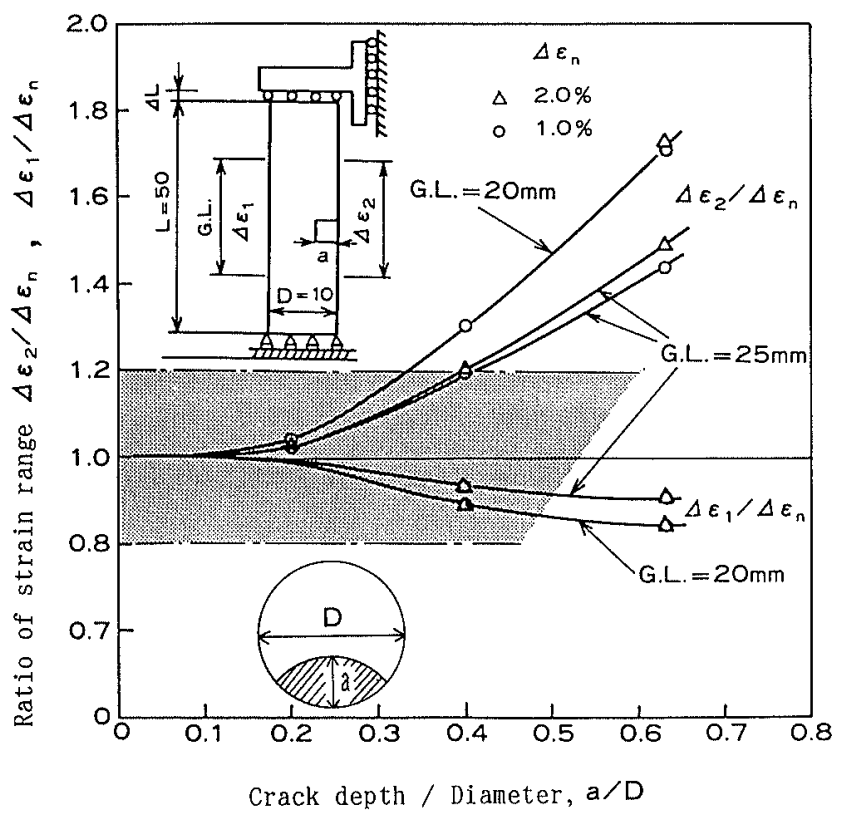

Fig. 8. Strain range on crack side and the back side. by $25 \%$ from its initial or stable value. When the crack has a semicircular shape, $a / D=0.4$ corresponds to surface crack length $2 c / D=1$.

Traces of high temperature fatigue cracks that remain on the fracture surfaces take on various shapes as shown in Fig. 10. Stress ratio $\alpha$ is also shown in Fig. 10. Cracked area corresponding to $\alpha=75 \%$ was $30 \%$ on the average. ${ }^{9)}$

First appearence of a cusp in hysteresis loop is one of recommended methods for defining $N_{x}{ }^{4)}$ In this study, the first cusp appeared when crack length was in the vicinity of $2 c / D=1 .^{9)}$ The method has the same physical meaning for criterion of $N_{x}$, but requires hysteresis loop of almost every cycle to detect the first appearance of the cusp.

\section{Summary}

In corporate research on VAMAS Low Cycle Fatigue activity, solutions were sought to the following problems. One is effects of a spot-welded thermocouple on test results and alternative methods of temperature measurement, and the other is physical meanings of the number of cycles to failure, i.e., fatigue life.

The results are summarized as follows.

(1) Effects of a Spot-welded Thermocouple

Based on past experience on ductile materials, spot-

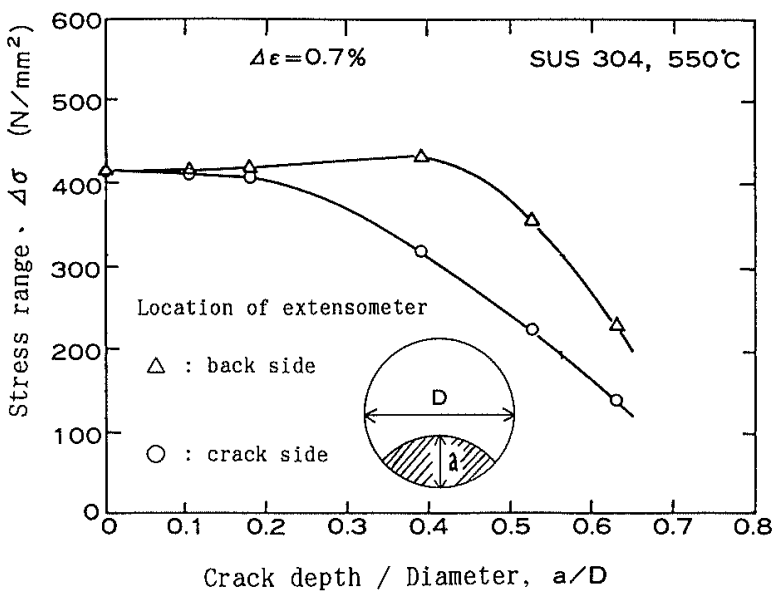

Fig. 9. Stress range depending on location of extensometer. $\alpha: \sigma_{\text {final }} / \sigma_{N f / 2} \times 100(\%)$
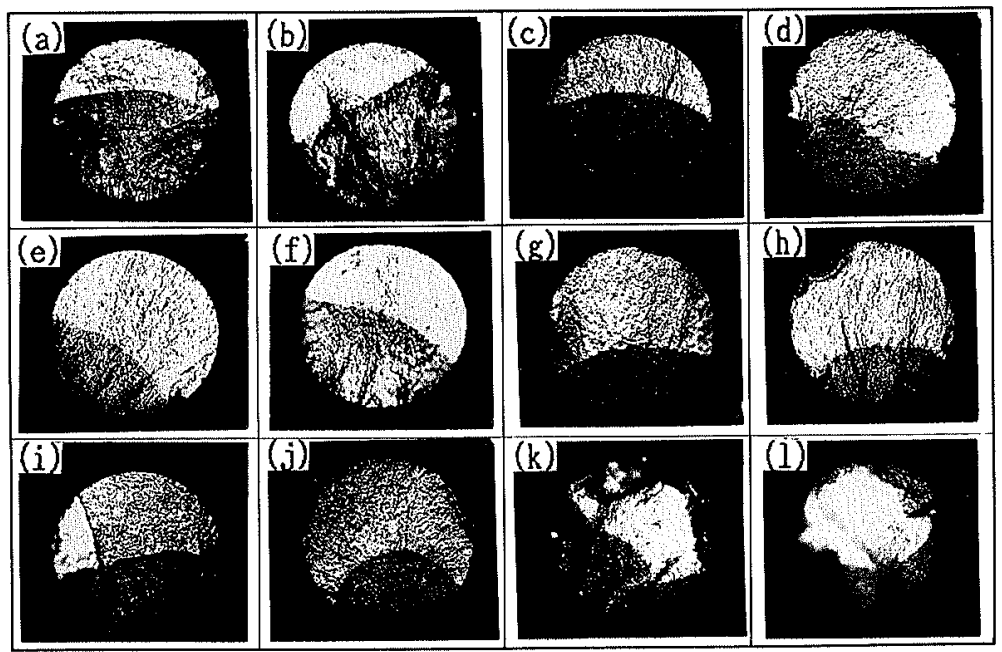

Fig. 10.

Traces of fatigue crack on fracture surface by oxidation.

(a) 304 Steel, $550^{\circ} \mathrm{C}, \alpha=42$, (b) 304 Steel, $500^{\circ} \mathrm{C}, \alpha=37$,

(c) $304 \mathrm{Steel}, 600^{\circ} \mathrm{C}, \alpha=47$, (d) 304 Steel, $550^{\circ} \mathrm{C}, \alpha=75$,

(e) 316 Steel, $550^{\circ} \mathrm{C}, \alpha=75$, (f) 316 Steel, $550^{\circ} \mathrm{C}, \alpha=55$,

(g) 304 Steel, $550^{\circ} \mathrm{C}, \alpha=75$, (h) 304 Steel, $550^{\circ} \mathrm{C}, \alpha=75$,

(i) $9 \mathrm{Cr}-1 \mathrm{Mo}$ Steel, $550^{\circ} \mathrm{C}, \alpha=70$,

(j) $9 \mathrm{Cr}-1 \mathrm{Mo}$ Steel, $550^{\circ} \mathrm{C}, \alpha=75$,

(k) 321 Steel, $600^{\circ} \mathrm{C}, \alpha=75$, (l) 316 Steel, $550^{\circ} \mathrm{C}, \alpha=75$ 
welding has been considered not to have effect on fatigue life. However, in this study, spot-welding of the thermocouple on the gage section decreased the fatigue life not only of high-strength superalloys but also middle-strength alloy such as $9 \mathrm{Cr}-1 \mathrm{Mo}$ steel.

(2) Alternative Method of Temperature Measurement

To prevent the above problem, a spot-welded thermocouple should not be used on the gage section even with induction heating systems. Rather a thermocouple with flattened tips should be attached to the gage section. When this type of thermocouple is used to measure temperature, another thermocouple must be spot-welded at the shoulder of the specimen for temperature control. Pyrometer type thermometer may also be used during the start of a test.

\section{(3) Definition of Fatigue Life}

Two definitions are recommended. One is a cycle in which tensile stress decreased by a predetermined percentage from decline tendency of tensile stress. The other is a cycle in which tensile stress decreased by a similar percentage from mid-life stress. By eithers definition, scattering is least and independent of the material or the predetermined percentage.

\section{(4) Suitable Predetermined Percentage}

It was shown experimentally and analytically that stress and strain differed depending on the relative location of crack and extensometer. Fatigue life is thus the cycle at $a / D=0.4$ or $2 c / D=1$, where $D$ is specimen diameter, $a$ semicircular crack depth and $2 c$ crack length on the specimen surface. At the cycle corresponding to the above conditions, the ratio of cracked area to whole cross section of round bar specimen becomes approximately $25 \%$. Twenty-five percent would thus appear to be the most appropriate stress drop value that determines fatigue life.

The results of this work were adopted in draft version of JIS (Japanese Industrial Standard) for the high temperature low cycle fatigue testing method proposed by the New Materials Center. The authors acknowledge the members of VAMAS-LCF Committee of The Iron and Steel Institute of Japan.

\section{REFERENCES}

1) VAMAS Bulletin No. 8, NPL, England, (1988).

2) G. B. Thomas and R. K. Varma: Final Report on Evaluation of Low Cycle Fatigue Test Data in the BCR/VAMAS Intercomparison Programme, NPL Report DMM(D) 50, NPL, England, (1990).

3) G. B. Thomas and C. Amzallag: Guidelines for a Comparative Programme, private communication, (1985).

4) Tentative Recommended Practice for Constant-Amplitude Low-Cycle Fatigue Testing, ASTM E606-77T, ASTM, (1978).

5) Guides for the Thermal Fatigue Tests of Metals, Vol. 24, ed. by High Temperature Strength Committee of SMSJ J. Soc. Mater. Sci. Jpn., (1975), 254.

6) Guides for High Temperature Low Cycle Fatigue Test of FBR Structural Materials, ed. by P. FCI Committee of WES Welding Eng. Soc. Japan, (1981).

7) G. R. Halford: Fatigue in Creep Range-Material Testing, Documentation and Interpretation, Recommended for ASME Boiler and Pressure Vessel Code Comm., (1975).

8) G. B. Thomas, R. Hales, J. Ramsdale, R. W. Suhr and G. Sumner: A Code of Practice for Constant-Amplitude Low Cycle Fatigue Testing at Elevated Temperature, Vol. 12, Fatigue Frac. Engng. Mater. Struc., (1989), 135.

9) Report on VAMAS Low Cycle Fatigue Round Robin Tests in Japan, ed. by VAMAS-LCF Committee of ISIJ, ISIJ, Tokyo, (1992).

10) S. Usami, Y. Fukuda and S. Shida: Trans. ASME, J. Pres. Vessel Tech., 108, (1986), 214.

11) Y. Fukuda, Y. Sato, K. Nakamura, Y. Takahashi and K. Kuwabara: J. Soc. Mater. Sci. Jpn., 39 (1990), 982.

(Originally published in Tetsu-to-Hagané, 78 (1992), 1431, in Japanese) 